\title{
СУЩНОСТЬ ИННОВАЦИОННОГО ИСПОЛЬЗОВАНИЯ ПРИРОДНО- ЭКОНОМИЧЕСКОГО ПОТЕНЦИАЛА ЗЕРНОПРОДУКТОВОГО ПОДКОМПЛЕКСА АПК И ПЕРСПЕКТИВЫ РАЗВИТИЯ ПО ИННОВАЦИОННОМУ ПУТИ "
}

\author{
(c) 2020 Зюкин Данил Алексеевич \\ кандидат экономических наук \\ Курская Государственная сельскохозяйственная академия имени И.И. Иванова, Россия, Курск \\ E-mail: nightingale46@rambler.ru
}

В статье показывается необходимость применения инновационных факторов для полноценного раскрытия природно-экономического потенциала зернопродуктового подкомплекса АПК. Представлено 4 сценария развития подкомплекса на стратегический период, в том числе с учетом полноценного и фрагментарного перехода к инновационно-инвестиционной модели.

Ключевые слова: зернопродуктовый подкомплекс, зерновое хозяйство, природно-экономический потенциал, инновационно-инвестиционная модель развития, сценарное прогнозирование, государственное регулирование, стратегия.

Зернопродуктовый подкомплекс крупный и очень важный элемент российского АПК, эффективность развития которого тесно переплетена с решением задач импортозамещения и продовольственной безопасности населения страны. Результаты производства в подкомплексе за 2019 год по основным показателям составили: сбор зерновых и зернобобовых культур в весе после доработки увеличился до 120,6 млн. т, при этом экспортировано 40,5 млн. т; комбикормов произведено 29,6 млн. т, что больше показателя 2018 года на 3,5\%; производство муки всех категорий составило 9,5 млн. т, что на $1,5 \%$ меньше уровня прошлого года и на 0,4 млн. т меньше показателя 2016 года, относительно которого наметился тренд на снижение производства. Таким образом, год следует признать относительно успешным, однако потенциал подкомплекса значительно выше. Не смотря на тот факт, что Россия является северной страной и во многих ее регионах возделывание зерновых культур трудно осуществлять, также имеется и ряд благоприятных зон для активного развития сельского хозяйства, обладающих качественными почвами, в том числе черноземами (регионы Центрального Черноземья входят в группу лидеров по относительному приросту урожаев зерна). Наличия доступа к морским торговым путям, в основном через Средиземноморские пути, позволяет расширять географии экспортных поставок российского зерна по странам Африки и Азии. Но чтобы лучше реализовать имеющийся у зернопродуктового подкомплекса природно-экономический потенциал необходимо искать возможности перехода к инновационно-инвестиционной модели его функционирования.

Инновационное использование природноэкономического потенциала зернопродуктового подкомплекса АПК возможно при полноценном или даже частичном переходе к инновационноинвестиционной модели, позволяющей более результативно и эффективно задействовать совокупность факторов различной природы. Результатом перехода к такой модели функционирования должно стать не только увеличение абсолютных показателей производства, но и обеспечение устойчивости и эффективности функционирования бизнес-субъектов на всех этапах воспроизводственной цепочки подкомплекса.

Именно проблема обеспечения устойчивости валовых сборов не позволяет обеспечивать поступательное развитие внутреннего рынка и особенно экспорта. На данный момент экспорт является основных стимулом к наращиванию урожаев зерна, тогда как внутреннее потребление даже сократилось в последний год, а урожаи существенно выше потребностей внутреннего рынка даже не в самый урожайный год (с 2014 года урожаи всегда превышают уровень в 100 млн. т, тогда как внутреннее потребление не превышает 80 млн. т). При этом перепады размеров экспорта зерна в 2016-2019 гг. составляют 10 и более млн. т, например, если сравнивать результаты последнего 2019 года и рекордного 2018 года, то снижение экспорта составило 15,7

\footnotetext{
" Статья подготовлена при финансовой поддержке РФФИ в рамках научного проекта № 18-310-00211
} 
млн. т. Нестабильность экспортных поставок была и раньше, например, провалы в 2004 и 2010 годах из-за природно-климатического фактора (рисунок 1). При этом Россия в то время еще не воспринималась как важный и стабильный игрок на мировом рынке зерна, тогда как откат в результатах в 2019 году и введение ограничительных квот в 2020 году является негативным сигналом для российских партнеров на мировом рынке зерна.

Надежность и качество всегда являются важными атрибутами для торговли на высококонкурентном мировом рынке агропродукции, причем, второй аспект не является сильной стороной российского зерна. Поэтому России выходить на новые рынки, учитывая сопутствующие неблагоприятные политические и географические факторы, далеко не всегда целесообразно, если в следующем сезоне не будет достаточно резервов к выполнению контрактных обязательств. Активная политическая позиция, ограничения мощностей перевалки глубоководных портов Азово-Черноморского бассейна, дополняемыми трудностью планировать объемы экспортных поставок, оставляют экспортную деятельность достаточно рискованной [1]. В частности, Россия уже ввела квоты на экспорт в первой половине 2020 года до июля, в ожидании ориентировочных результатов по урожаю ближайшего года, что не способствует росту инвестиционной привлекательности зернового хозяйства.

Применение инновационных факторов в использовании природно-экономического потенциала зернопродуктового подкомплекса как раз способствует устойчивости урожаев, так как даже при частичном переходе к инновационноинвестиционной модели будут более эффективно задействоваться экономико-производственные факторы. Ключевыми направлениями стратегического развития зернопродуктового подкомплекса будут те, которые позволяют решать фундаментальные и наиболее острые проблемы, обладающие при этом высоким синергетическим эффектом. Наиболее существенными проблемами, решение которых способствовало улучшениям на всей воспроизводственной цепочке зернопродуктового подкомплекса АПК, являются система селекции и семеноводства, а также производственно-логистическая инфраструктура. Итогом разрушения отечественной системы селекции и семеноводства стало снижение качества посадочного материала, низкий уровень использования районированных семян, рост доли на рынке семян импортных сортов, минимальный уровень новых отечественных гибридов, доведенных до массового производства. В свою очередь, критика состояния производственно-логистической инфра-

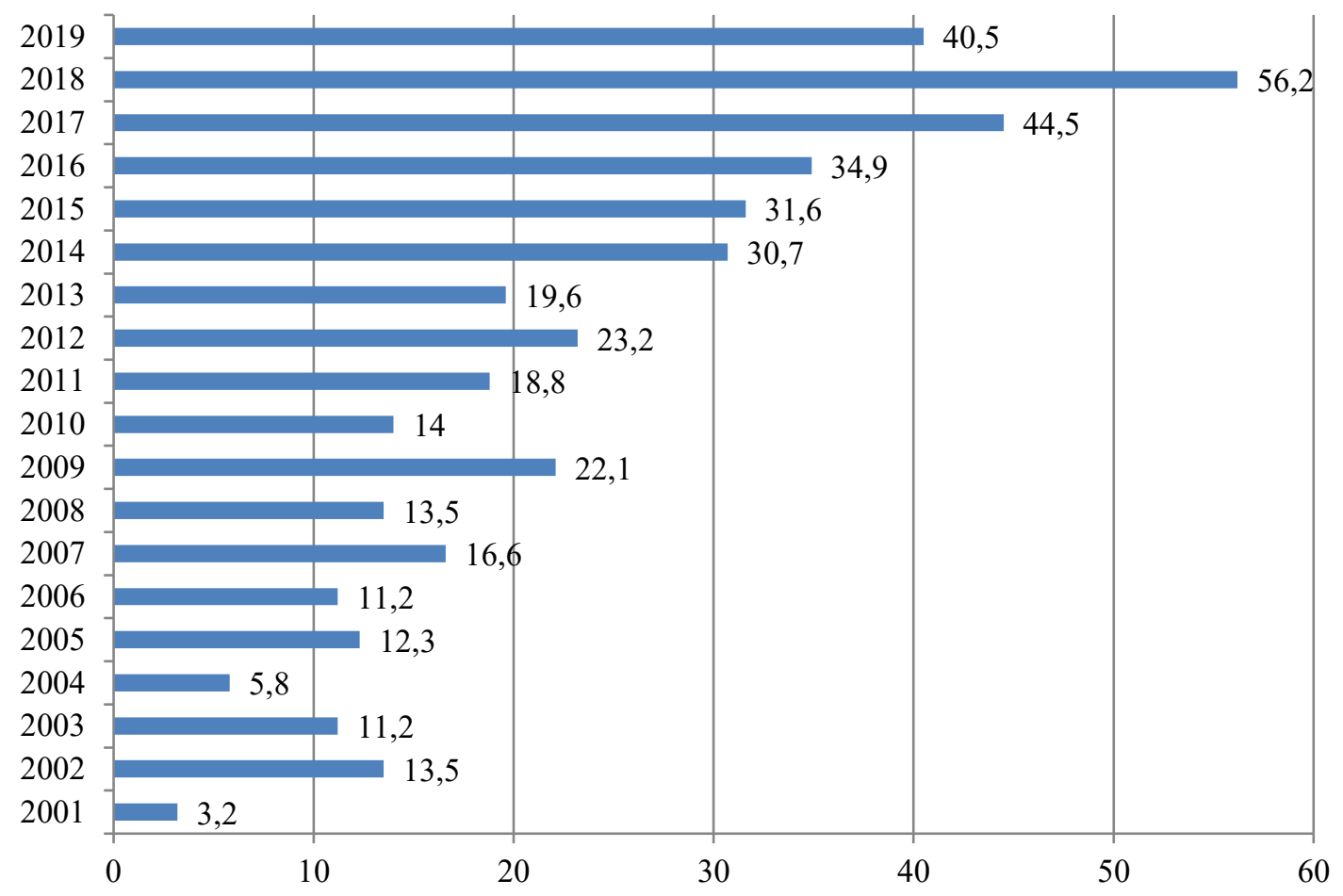

Рисунок 1. Динамика экспорта российского зерна в 2001-2019 гг. 
структуры сводится к тому, что она не соответствует текущим объемам производства и транспортировки потоков зерна на внутреннем рынке и на экспорт.

Решение этих проблем требует как крупных инвестиций, так и задействования научноинновационного потенциала, что вписывается в концепцию развития подкомплекса только в рамках инновационно-инвестиционной модели. Поиск инвестиций для модернизации производственно-логистической инфраструктуры при всей значимости этой задачи крайне сложен в виду традиционной невысокой инвестиционной привлекательности российского АПК, что усугубляется кризисным состоянием экономики, в котором она находится с 2014 года. На данный момент ситуация усугубляется кризисом на нефтяном рынке, повлекшим девальвацию рубля (хотя непосредственно для экспорта это положительный фактор) и уход инвесторов с торговых площадок России, что дополняется непонятными перспективами с организацией карантина в стране из-за коронавируса.

В такой ситуации важно какую позицию будет занимать государство. Будет ли это и дальше путь компенсаций недостатков имеющейся финансовой модели и транспортной системы, в частности, труднодоступность «длинных денег» на реализацию инфраструктурных проектов и высокие тарифы на перевозку зерна для межрегионального обмена и на экспорт, что, как показала практика, не решало проблем, препятствующих быстрой и эффективной логистике зернопотоков внутри страны и на экспорт. Будет ли осуществлен переход к приоритетному задействованию инструментов преимущественно экономического регулирования, существенно улучшающих условия реализации инфраструктурных проектов в зернопродуктовом подкомплексе АПК за счет мягкой и гибкой монетарной и фискальной политики. Как будут реализовываться крупные проекты по возведению элеваторных мощностей, которые следует выполнять в комплексе с развитием железнодорожной сети, что требует обеспечения государственной координации между аграрным бизнесом и РЖД [2]. На сколько полноценно будет реализован проект использования облачных технологий для оптимизации процессов производства, хранения и транспортировки зерна. Решение всех этих ключевых вопросов зависит от модели государственного и экономического регулирования развития производственно-логистической инфра- структуры зернопродуктового подкомплекса. А значит, именно государство может и должно стать драйвером к переходу к инновационноинвестиционной модели развития зернопродуктового подкомплекса, по крайней мере, в вопросе модернизации инфраструктуры.

Учитывая совокупность переплетенных проблем зернопродуктового подкомплекса, свойственных всему АПК и дополняемых текущей неблагоприятной экономической ситуацией в стране, на любом этапе воспроизводственной цепочки подкомплекса крайне трудно обеспечить более эффективное использование его природно-экономического потенциала за счет имеющихся инструментов. Вызывает сомнение и способность за счет успехов и коренного изменения типа хозяйствования на одном из элементов воспроизводственной цепочки обеспечить развитие всего подкомплекса. Быстро решить вопросы по совершенствованию работы системы селекции и семеноводства и выведению новых сортов и гибридов, производства и подготовки посевного материала и модернизации производственно-логистической инфраструктуры в силу экономических и биологических факторов нельзя. Поэтому в краткосрочном периоде наиболее высокая мультипликативная роль среди элементов воспроизводственной цепочки подкомплекса принадлежит этапу производства зерна. Всплески урожаев и благоприятная ценовая конъюнктура были катализаторами определенных улучшений в зерновом хозяйстве, однако перейти всему подкомплексу на более высокий уровень эффективности не удавалось, а при возникновении неблагоприятных факторов сразу происходил откат в развитии, например, в 2003 году и 2010-2012 годах.

Потому важно обеспечить устойчивость валовых сборов зерна, а для этого необходимо пересмотреть подходы к интенсификации производства. Сейчас наиболее популярными и востребованными способами интенсификации являются интенсивные факторы увеличения производственных затрат в расчете на 1 га посевов зерновых культур, в первую очередь, за счет расходов на минеральные удобрения. Такой подход, как показывает практика хозяйствования, весьма эффективен - с повышением затрат на приобретение минеральных удобрений в расчете на 1 га посевов зерновых обеспечивается прибавка в урожайности и прибыли. С другой стороны, следует помнить, что помимо экономических ограничений в виде убываю- 
щей предельной полезности бесконтрольное использование этого фактора может нанести урон окружающей среде [3]. Поэтому Алтухов А.И. и Силаева Л.П. видят приоритетом использование биологического фактора, являющегося менее затратным способом удешевления производства зерна, что определяет организацию интенсивной селекционной работы в качестве приоритета среди направлений развития НТП в зерновом хозяйстве [4]. К тому же качественный посевной материал способен обеспечить создание синергетического эффекта при использовании в комплексе с другими факторами интенсификации, в особенности, с удобрениями.

Без сомнения, инновационный путь может полноценно раскрыть природно-экономический потенциал зернопродуктового подкомплекса, но в современных условиях кризиса российской экономики большая часть аграриев в лучшем случае способна только перенимать уже внедренные в практику инновации, осваивая их только с помощью информационноконсультативных ресурсов. Поэтому в условиях активного внедрения цифровых технологий во все сферы социальной и производственной деятельности эти инновации могут стать наиболее доступными и эффективными для аграрного бизнеса.

При глобальном переходе на цифровые технологии отечественные производители смогут занимать различные высокодоходные ниши в наукоемких услугах для сельского хозяйства и пищевой промышленности, среди которых - передовые решения в области биотехнологий, информационно-коммуникационных технологий, робототехники, а также восстановление природной среды и проектирования экосистем. Цифровизация земледелия и сельского хозяйства - это, в том числе, и инструмент масштабной программы цифровизации сел, подключение их к цифровой инфраструктуре, преодоление «цифрового» разрыва и социальноэкономического возрождения сельских территорий [5].

При текущих технологиях возделывания зерновых культур будет и дальше сохраняться высокая нестабильность валовых сборов и зависимость от благоприятности природноклиматических условий. Для формирования долгосрочного прогноза мы предлагаем использовать индикативное планирование, в котором представляется 4 сценария развития ситуации. В инновационном сценарии идет расчет на существенный скачок в применяемых агротехнологиях, за счет которых удастся повысить урожайность и валовой сбор зерна. Умеренно-оптимистичный сценарий предполагает частичный переход к инновационноинвестиционной модели при умеренно-благоприятных природно-климатических условиях. Вторая пара сценариев основывается на реалистичной модели развития ситуации в аграрной сфере России, характеризуемой незначительными подвижками в переходе к инновационному типу земледелия и организации менеджмента. Оптимистично-консервативный сценарий предполагает локальные улучшения технологий возделывания зерновых культур и благоприятные природно-климатические условия. В свою очередь, пессимистично-консервативный сценарий включает отсутствие благоприятных природно-климатических условий и сохранение комплекса существующих проблем зернопродуктового подкомплекса АПК. Внутреннее потребление также соответствует характеру сценария. Так, для инновационного сценария, в рамках которого ожидается рост уровня развития и зернопотребляющих отраслей, тогда как в консервативном сценарии потребление зерна осталось на текущем уровне. Экспорт формируется на принципах инструмента санации зернового рынка и определяется как разница между валовым сбором незначительного наращивания переходных запасов резервных фондов (таблица 1).

Комплексное развитие зернопродуктового подкомплекса АПК по инновационноинвестиционной модели создает значительные возможности для удовлетворения внутреннего потребления и активной экспансии российского зерна на мировом рынке. Обязательной составляющей для такого перехода является массовое тиражирование в практике возделывания зерновых культур эффективных инновационных технологий. Вместе с этим очень важно на уровне государства решить комплекс стратегических проблем: модернизация и развитие логистической инфраструктуры для целей внутреннего рынка и экспорта; восстановление системы селекции и семеноводства; государственная поддержка инновационных и инфраструктурных проектов; улучшения рыночных процессов путем снижения монопольного влияния крупных зернотрейдеров; рост доли участия непосредственных производителей зерна в доходах от экспорта. 
Таблица 1. Сценарии развития зернопродуктового подкомплекса АПК России к 2030 году

\begin{tabular}{|l|c|c|c|c|}
\hline \multirow{2}{*}{\multicolumn{1}{|c|}{ Показатель }} & \multicolumn{4}{|c|}{ Сценарии стратегического развития } \\
\cline { 2 - 5 } & Инновационный & $\begin{array}{c}\text { Умеренно- } \\
\text { оптимистичный }\end{array}$ & $\begin{array}{c}\text { Оптимистично- } \\
\text { консервативный }\end{array}$ & $\begin{array}{c}\text { Пессимистично- } \\
\text { консервативный }\end{array}$ \\
\hline $\begin{array}{l}\text { Валовой сбор зерновых, } \\
\text { млн. т }\end{array}$ & 155 & 140 & 132 & 120 \\
\hline Экспорт зерна, млн. т & 65 & 55 & 49 & 40 \\
\hline $\begin{array}{l}\text { Внутреннее потребле- } \\
\text { ние зерна, млн. т }\end{array}$ & 88 & 83 & 81 & 78 \\
\hline
\end{tabular}

\section{Библиографический список}

1. Зюкин Д.А. Развитие экспортного потенциала зернового хозяйства России // Экономика сельскохозяйственных и перерабатывающих предприятий. 2019. № 1. С. 58-61.

2. Зюкин Д.А. Модель экономического и государственного регулирования развития инфраструктуры зернового рынка // Международный сельскохозяйственный журнал. 2020. № 1. С. 47-50.

3. Зюкин Д.А., Солошенко Р.В. Оценка направлений интенсификации как условия повышения результативности и эффективности производства зерна // Вестник Курской государственной сельскохозяйственной академии. 2019. № 8. С. 198-203.

4. Алтухов А.И., Силаева Л.П. Совершенствование производства зерна - основа его инновационного развития // Никоновские чтения. 2018. № 23. С. 30-33.

5. Алтухов А.И., Дудин М.Н., Анищенко А.Н. Глобальная цифровизация как организационно-экономическая основа инновационного развития агропромышленного комплекса РФ //Проблемы рыночной экономики. 2019. № 2. C. 17-27. 